
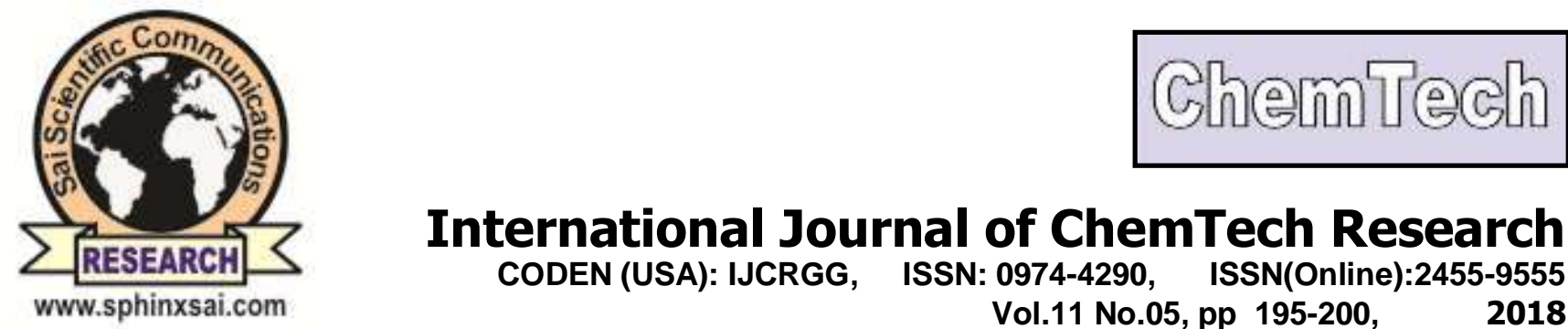

International Journal of ChemTech Research CODEN (USA): IJCRGG, ISSN: 0974-4290, ISSN(Online):2455-9555

Vol.11 No.05, pp 195-200,

2018

\title{
Conceptual Errors and Alternative Conceptions on the Periodic Table of Chemical Elements
}

\author{
Candelaria N. Tejada ${ }^{1}$, Cielo Chicangana ${ }^{2}$, Diofanor Acevedo*3 \\ 1,2 Faculty of Engineering, Chemical Engineering program, Research Group IDAB, \\ University of Cartagena Av. El Consulado, St. 30 No. 48-152. Colombia. \\ ${ }^{3}$ Faculty of Engineering, Research Group Innovation, Agricultural and Agro-industrial \\ Development, University of Cartagena Av. El Consulado, St. 30 No. 48-152. Colombia.
}

\begin{abstract}
The objective of this work was to find the possible conceptual errors and alternative conceptions that students have regarding the periodic table of chemical elements and derived themes such as valence, links, compounds and molecules. This was done by applying a test in order to classify, describe, analyze and interpret the data obtained, organizing the information into categories. It was found that the 40 participating students present heterogeneity in terms of concepts such as valence, criteria for classifying chemical elements in the periodic table, transition metals and internal transition metals, as well as nule information regarding the formation of coordination complexes. This is interpreted as a lack of emphasis and clarity in providing concepts in the teaching-learning process.

Keywords: compounds, conceptual errors, chemical links, periodic table, chemical valence.
\end{abstract}

\section{Introduction}

One of the most relevant concepts within those addressed in chemistry education is the periodic table, since it allows us to know the constitution of matter, as well as the properties of each of the substances that form it, without which it cannot understand the reactions that take place in our world, the nature of the changes that take place, nor continue advancing in the knowledge that this science encompasses [1, 2].(Garritz, 2007).However, the empty meaning that the learner greatly appreciates what he or she has to learn about it takes up a great deal of information [3]. (Chamizo et al., 2004).Izquierdo[4] (2004) analyzes the situation of chemistry education and suggests adapting its contents, languages and methods to the demands of current scientific training, especially for the new social purposes of' scientific literacy' that must be taken into account. As for the methodology used by teachers, it states that they should have a broad view of how it is taught, thinking about new disciplinary proposals, rational and reasonable, in which theory and practice are properly related, which will lead to contextualized programs and modeling proposals that ensure that the concepts to be taught will be appropriate, prioritizing in the semantic sense of the theory rather than syntactic. This provides objectives that encourage students to intervene in them and to think; the new strategies require a new profile of teaching staff that also reaches the level of university graduate in chemistry dedicated to making students become' competent': as people, as citizens, as scientists [2]. 
In the teaching-learning of chemistry, traditionally there have been problems of both pedagogical and didactic nature. Therefore, the teaching of chemistry must be approached from different approaches and styles. This is why there are researchers who use didactics for teaching concepts in chemistry, based on the dialectical conception of knowledge and ideas of activity theory and teaching, based on the formation by stages of mental actions, under the scheme of subordinate learning. Supported by the theories of Theory of Vigotsky, Leantiev, Galperin, Talizina and Ausubel; proposing a method for the student to carry out the integrative reconciliation, which allows him to develop a greater capacity for the significant assimilation of concepts related to chemistry, specifically the concept of valence[5].(Tejada et al., 2013a).

On the other hand, there is the way in which the majority of teachers teach it; which undoubtedly has a significant influence on the students making a genuine appropriation of the concept, as shown in the study carried out by Tejada et al., [6], (2013b), who studied the way in which the students express the models of atoms, evidencing the influence of the different ways in which the teachers teach and the diverse forms and styles in which the students learn.

This is how the teaching of chemistry, its concepts, formation of chemical compounds, as well as the concept of chemical valence, demands that new ideas must be subordinate to previous knowledge such as: Atom concept, electronic structure of the atom, Hund's rule, Pauli's exclusion principle, anion and cation concepts, which are implicit in all knowledge contained in the periodic table [5, 7]. (Tejada et al., 2013a).

This is why in the present research, an identification of conceptual errors was carried out and it was also sought to find the alternative conceptions that a group of students of the inorganic chemistry course have on the periodic table; being aware and giving relevance to the importance, which should have the same in the teaching of chemistry.

\section{Experimental}

This research is of a descriptive nature, where the information gathered during the implementation of didactics by teachers in the teaching and learning process of the periodic table, became a fundamental element to describe through categories the concepts, conceptual errors and alternative conceptions that students have at the time of internalizing the learning on periodic table. Forty students from the inorganic chemistry department of the engineering faculty of the University of Cartagena (Colombia) participated. In addition, three investigators; represented in a participating observer and two non-participating observers, who triangulated information collected.

A previous concept test was applied as shown below, in which students selected with an $\mathrm{X}$ the answer they considered correct. The test consisted of 10 questions referring to students' previous concepts regarding the periodic table of chemical elements: 1). How are the elements organized in the periodic table?, 2) Basic concepts on electronic configuration and its relation with the periodic table, 3). Basic concepts for identifying and discriminating between metals, non-metals and transition metals, 4). Chemical difference between metals and non-metals, 5. Basic concepts on chemical bonding and differentiates the different types of bonding, 6) How do chemical bonds form?, 7). Differences between ion bond and covalent bond, 8). Define chemical valence, 9). Do you know the concept of chemical valence proposed by Alfred Werner? and 10). Concept of formation of chemical compounds and their relationships with ionic bonding, covalent bonding and some explanations related to the properties of the elements.

The information provided was analyzed and categories related to how the students conceive the organization of the elements in the periodic table were identified and 3 subcategories were identified, within this table. To complement the above, and in order to identify alternative conceptions, basic knowledge and conceptual errors, an entrance test or pre-concept test was also conducted, where the 40 students were asked to take a sheet of paper and asked questions regarding the periodic table, where the students' basic concepts on a periodic table were identified as a category, which they were related to the following criteria: which has seven periods, 18 groups, indicating the 8 representative groups, 10 transition groups and 14 internal transition groups. 


\section{Results and discussions}

With respect to question No. 1, where students are probed about how the elements are organized in the periodic table, the information provided by them was analyzed and a category related to the way students conceive the organization of the elements in the periodic table was identified and 3 subcategories were identified, which are listed below:Thirty-one students out of forty, consider that the elements are organized by atomic numbers in the periodic table. Seven students consider that the elements are organized by the number of protons. With respect to these two subcategories, it is striking that the students did not relate the concept of atomic number to the number of protons, which is a distinguishing characteristic among the chemical elements.

In this sense, the great majority of students do not have sufficient clarity about the classification criteria of the elements in the periodic table, which is in ascending order of their atomic number, which corresponds to an element in their number of protons; this is of great importance since the periodic table of the chemical elements is a fundamental source of consultation, which has much explicit information about the chemical properties of the elements, including here the chemical valence. At the same time, it allows very logical and accurate predictions to be made about the behaviour of the elements when forming compounds, which is related to their position in the periodic table, as well as information alluding to physical properties.

As a final subcategory, two students were identified who consider that the elements are organized in the periodic table by the number of electrons of the last energy level. In these students a conceptual error was evidenced by the reasons described in the previous subcategory, this may be due to the fact that in some cases, especially in the representative elements, that is to say those of the groups, the number of electrons of the last energy level corresponds to the number of the group to which it belongs, which is not a rule that can be generalized in the entire periodic table.

In relation to question number 2 of the previous concept test, the macro-category identified was: basic concepts on electronic configuration and its relation with the periodic table, which is related to the electronic distribution that implies a hierarchy between the occupied sublevels and the correspondence that this has with the location of the element in the periodic table; the interaction between these aspects generated the following subcategories: It was found that 17 students out of 40 correctly perform the electronic distribution and relate the representative ones to the transition ones and are precise to use and place elements in the periodic table, (See Figure 1).

$$
\begin{aligned}
& Z=12 \\
& 1 s^{2} 2 s^{2} 2 p^{6} 3 s^{2} \text { It has } 2 e^{-} \text {in the last energy level } \\
& \text { Group III } A \\
& \text { Period: } 3
\end{aligned}
$$

Figure 1.Student answer $\mathbf{N}^{\circ} 2$ to question 2 of the test

It was also found that 10 students out of 40 perform electronic distribution correctly but are inaccurate to place the element in the periodic table. For example, the student $\mathrm{N}^{\circ} 38$ is cited:

$$
\begin{aligned}
& Z=21 \\
& 1 s^{2} 2 s^{2} 2 p^{6} 3 s^{2} 3 p^{6} 4 s^{2} 3 d^{1} \\
& \text { Group. 3A It has one } e^{-} \text {in the last energy level } \\
& \text { Period. } 3
\end{aligned}
$$

Figure 2.Response of student $N^{\circ} 38$ to question 2 of the test 
It was also identified that six students simply perform electronic distribution correctly. For example, the student $\mathrm{N}^{\circ} 3$ is cited:

$$
\begin{aligned}
& Z=35 \\
& 1 s^{2} 2 s^{2} 2 p^{6} 3 s^{2} 3 p^{6} 4 s^{2} 3 d^{10} 4 p^{5}
\end{aligned}
$$

Figure 3. Student response $\mathrm{N}^{\circ} 3$ to question 2 of the test

With respect to the last two subcategories, it was believed that these events of inaccuracy in locating chemical elements to a specific group in the periodic table may be due to a lack of clarity on the part of teachers when teaching. Another subcategory that emerged from the analysis is related to three students who incorrectly perform electronic distribution and its relationship to the periodic table. For example,the student $\mathrm{N}^{\circ} 39$ is cited:

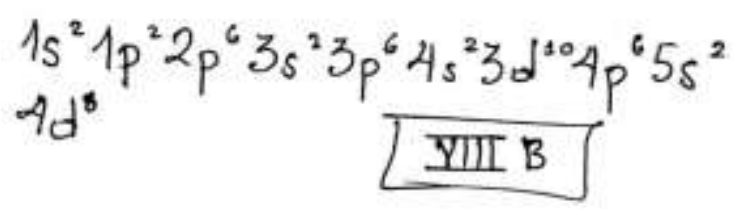

Figure 4.Student answer $\mathrm{N}^{\circ} 39$ to question 2 of the test

Finally, four students were identified who perform the electronic distribution correctly and demonstrate skills to use it and place the elements in the periodic table but do not differentiate between the representative and the transition ones. For example, the student $\mathrm{N}^{\circ} 28$ is cited:

$$
\begin{aligned}
& z=34 \\
& 1 \delta^{2} 2 \delta^{2} 2 p^{6} 3 s^{2} 3 p^{6} 4 s^{2} 3 d^{10} 4 p^{4} \\
& \text { Group: } \\
& \text { Poriod: } 4 \\
& \text { Last level \# } e^{-}: 4
\end{aligned}
$$

Figure 5.Student's answer to question 2 of the test No. 2

In relation to questions 3 and 4 of the previous concept test, the macro category identified is: basic concepts to identify and discriminate between metals, non-metals and transition metals, which is related to the chemical difference between metals and non-metals; the question assesses the student's discrimination between metals, non-metals and transition metals in a list of chemical elements, the interaction between these aspects generated the following subcategories: It was found that 1 student out of 40 recognizes the chemical behavior of metals and ranks metals, non-metals and transition metals in a given list. Likewise, 7 students out of 40 recognize the chemical behavior of metals and classify metals and non-metals in a given list, being imprecise with transition metals. In the latter subcategory, there was an inconvenience with the appropriation of the concept of transition metals, which may be due to the teacher's lack of clarity, since this group of metals is generally not given sufficient attention. 8 students recognize the chemical behavior of metals and recognize them incompletely in a given list. 15 students do not recognize the chemical behavior of metals and misclassify them from a given list. 
Six students do not recognize the chemical behavior of metals and is inaccurate in ranking on a given list of metals, non-metals and transition metals. Another 4 students recognize the chemical behavior of metals and are imprecise in their classification on a given list. This group of students present significant conceptual flaws, which we believe may be due to the way the teacher approached the subject, as well as the clarity provided during classes.

In relation to questions 5,6 and 7 of the previous concept test, the macro category identified is: basic concepts on chemical bonding and differentiates the different types of bond, which is related to the formation of a chemical bond, differentiating between ionic and covalent bonding; the interaction between these aspects generated the following subcategories: It was found that 17 students out of 40 explain the formation of a chemical bond differentiating between ion bond and covalent bond. Twelve students present insufficient information about a chemical bond and the differentiation between them. Likewise, 9 students were found to be imprecise in explaining the formation of the chemical bond, as well as the differentiation between them. Finally, in this subcategory he found that two students do not present any information at all.

With regard to the last two categories, inaccurate and insufficient responses can be attributed to conceptual errors, which can be corrected by providing greater clarity on the part of the teacher when the lessons are retaken until these gaps can be corrected. Regarding question number 8 of the previous concept test, it was identified as a macro category: students' conceptions of the concept of valence, which are related to electrons of the last energy level, types of bond, bonding capacity, levels or layers of energy; the interaction between these allowed the following subcategories to emerge: 7 students out of 40 were identified as relating chemical valence to bonding capacity. Likewise, it was identified that 13 students of 40 express the chemical valence as the electrons of the last energy level. In the same sense, eight students relate chemical valence to type of bond. Three students relate chemical valence to layer or energy level.

In general in this macro-category, it could be inferred that the great majority of students associate several concepts with chemical valence, which means that there is no homogeneous concept of valence, attributing a variety of conceptions to it. Thus, for a group of valencia students it has to do with the number of electrons of the last level, for others it has to do with the energy levels, for others it has to do with the type of link and for others it has to do with the capacity of link. This is very significant for this research, since it allows us to make approximations on how teachers approached this knowledge in addition to the didactics they used for the development of the program, as well as the clarity at the time of teaching. In relation to question number 9 of the previous concepts test, it was identified as macrocategory: basic knowledge of the students about the concept of valencia proposed by Alfred Werner. We identified that 39 students out of 40, do not know Alfred Werner's proposal regarding the concept of chemical valencia, and only one student provided information on Alfred Werner's proposal, although insufficient.

This tells us about the incomplete way in which the concept of valence has been oriented, which is only informative and impartial since it only applies to representative elements where the valence that explains the formation of molecules is primary. The concept of secondary valencia, proposed by Alfred Werner, is unknown in the didactics used. In relation to question number 10 of the previous concepts test, it was identified as macro category: students' concepts on the formation of chemical compounds, related to ionic bonding, covalent bonding and some explanations related to the properties of the elements, the interaction between these allowed the following subcategories to emerge.

Based on the information requested in question 10, 4 students explain the compounds supported only by the ion and covalent bond. A student classifies compounds into ionic and covalent, explaining their formation, recognises coordination compounds but does not explain their formation. Three students recognize the ionic and covalent compounds and poorly explain the coordination compounds, alluding to other properties of the elements. Seven students explain briefly the formation of ionic bonding. Fourteen students do not report any information (NOREINF). Eleven students report information that is not relevant.

Only one student identifies the seven periods, 8 representative groups, 10 transition groups and 14 internal transition groups. This may be due to personal curiosities that the student satisfies after orientation but not an orientation that provokes genuine learning in him/her. 3 students identified seven periods and 18 groups with no differentiation between representative and transition groups and correctly represent internal transition groups; the low number of students in this group supports what was expressed in the previous one. 11 students 
out of 36 identify seven periods, 8 representative groups, 10 transition groups, but do not correctly identify the elements of internal transition. 8 students identified seven periods and 18 groups with no differentiation between representative and transition periods. Internal transition groups are not correctly represented. 11 students out of 36 identify the seven periods without correct representation of the 18 groups, without differentiation between representative and transitional and without correct representation of the internal transition groups. These situations are indicative of the exclusion or scant importance or very little usefulness of all the chemical elements in the teaching process, this does not generate genuine and complete learning, but concepts (rather information) incomplete.

Regarding question 2, which asks how the elements are organized in the periodic table. The students' conception of the organization of the elements in the periodic table was identified as a macrocategory; the subcategories arise from the interaction of the following criteria: the recognition of groups and periods in the structure of the periodic table, and the relationship between electronic distribution and the periodic table. 16 students out of 36, did a simple classification of the elements by groups and periods. 13 students out of 36, ranked by groups and periods based on atomic number. 2 students were classified by groups and periods according to valence electrons. Finally, two students ranked according to physical and chemical properties. This situation, which shows heterogeneity in the classification of chemical elements in the periodic table, shows that there is ignorance of the classification criterion with which it was designed, which allows us to infer that in this respect there is no marked emphasis on the orientation that allows the student such recognition. This says that it is a concept that is oriented to subjective criteria of teachers but does not obey the scientific guidelines that have been built, which in turn is also unknown in the process, which is based on finished truths.

\section{Conclusions}

In most of the categories, alternative conceptions were found which are insufficient and not pertinent when answering the questions adequately, as well as conceptual errors that may be due to lack of clarity and interest in the teaching-learning process of the periodic table of chemical elements; generating gaps in learning and incomplete knowledge. On the other hand, the heterogeneity in classifying the chemical elements in the periodic table shows the ignorance of the criteria used by Mendeleiev for his organization, concluding that there is no emphasis on the orientation of the basic concepts imparted to students around the conceptual basis of the periodic table.

\section{References}

1. Torres, G. E. P., Loeza, W. F. B., \& Quintero-Mármol, N. L. R. "Desarrollo de un Módulo Instruccional para la Enseñanza de la tabla periódica", Educación y ciencia,vol. 3, no. 7(42), pp. 44-56, 2015.

2. Garritz A. Mendeleiev, muerto hace cien años. El papel de una madre (editorial), Educ.quím. [En Línea], vol. 18, no. 3, pp. 178-180, 2007.

3. Chamizo, J.; Nieto, E. y Sosa, P. La enseñanza de la química. Tercera parte. Evaluación de los conocimientos de química desde secundaria hasta licenciatura. Educ. quím. [En línea], vol. 15, no. 2, pp. 61-65, 2004.

4. Izquierdo, M. "Un nuevo enfoque de la enseñanza de la química: Contextualizar y modelizar", J. Argent. Chem. Soc., vol. 92, no. 4-6, pp. 115-136, 2004.

5. Tejada, C., Chicangana, C. y. Villabona, A. "Enseñanza de la química basada en la formación por etapas de acciones mentales (caso enseñanza del concepto de valencia)", Revista Virtual Universidad Católica del Norte, vol. 38, pp. 143-157, 2013.

6. Tejada C, Gattas C. y A. Villabona, "Concepciones alternativas y errores conceptuales de estudiantes sobre modelos atómicos en química2, RevistaEntornos, vol. 26, no. 2, pp. 267-274, 2013.

7. Mendoza, A, Acevedo, D. y Tejada, C. "Theory of Stepwise Forming of Mental Actions (SFMA) in teaching and learning the concept of chemical valence", Formaciónuniversitaria, vol. 9, no. 1, pp. 7176, 2016. 